\title{
A comparison of the effects of cheese and butter on serum lipids, haemostatic variables and homocysteine
}

\author{
Anne S. Biong ${ }^{1,2}$, Hanne Müller ${ }^{3,4}$, Ingebjørg Seljeflot ${ }^{5}$, Marit B. Veierød ${ }^{6}$ and Jan I. Pedersen ${ }^{1,3 *}$ \\ ${ }^{1}$ Institute of Basic Medical Sciences, Department of Nutrition, University of Oslo, PO Box 1046 Blindern, 0316 Oslo, \\ Norway \\ ${ }^{2}$ TINE Centre for Research and Development, 0902 Oslo, Norway \\ ${ }^{3}$ Akershus University College, 1356 Bekkestua, Norway \\ ${ }^{4}$ Department of Animal and Aquacultural Sciences, The Agricultural University of Norway, PO Box 5003, 1432Ås, Norway \\ ${ }^{5}$ Centre for Clinical Research, Ullevål University Hospital, 0407 Oslo, Norway \\ ${ }^{6}$ Section of Medical Statistics, University of Oslo, 0317 Oslo, Norway
}

(Received 3 February 2004 - Revised 17 June 2004 - Accepted 9 July 2004)

\begin{abstract}
Milk fat contains considerable amounts of saturated fatty acids, known to increase serum cholesterol. Little is known, however, about the relative effect of different milk products on risk factors for CHD. The aim of the present study was to compare the effects of Jarlsberg cheese (a Norwegian variety of Swiss cheese) with butter on serum lipoproteins, haemostatic variables and homocysteine. A controlled dietary study was performed with twenty-two test individuals (nine men and thirteen women) aged 23-54 years. The subjects consumed three isoenergetic test diets, with equal amounts of fat and protein, and containing either cheese $(\mathrm{CH}$ diet), butter + calcium caseinate (BC diet) or butter + egg-white protein (BE diet). The study was a randomised cross-over study and the subjects consumed each diet for 3 weeks, with 1 week when they consumed their habitual diet in between. Fasting blood samples were drawn at baseline and at the end of each period. Serum was analysed for lipids and plasma for haemostatic variables and homocysteine. Total cholesterol was significantly lower after the $\mathrm{CH}$ diet than after the $\mathrm{BC}$ diet $(-0.27 \mathrm{mmol} / \mathrm{l} ; P=0.03)$, while the difference in LDL-cholesterol was found to be below significance level $(-0.22 \mathrm{mmol} / \mathrm{l} ; P=0.06)$. There were no significant differences in HDL-cholesterol, triacylglycerols, apo A-I, apo B or lipoprotein (a), haemostatic variables and homocysteine between the diets. The results indicate that, at equal fat content, cheese may be less cholesterol increasing than butter.
\end{abstract}

Coronary heart disease: Serum cholesterol: Dairy products: Fibrinolysis: Calcium

Milk fat is rich in saturated fat and cholesterol, known to increase serum cholesterol (Hegsted et al. 1993; KrisEtherton \& Yu, 1997). Populations with a high intake of saturated fat have a high CHD mortality (Renaud \& Lanzmann-Petithory, 2001), and this is one reason why the intake of dairy products has been considered a main factor related to the high incidence of CHD in Western countries. However, the association between the intake of dairy products and the risk of CHD is somewhat controversial. Some observational studies have shown that diets rich in milk and butter are hypercholesterolaemic (Katan et al. 1995; Kushi et al. 1995; Pietinen et al. 1996; Moss, 2002) while others provide no convincing evidence that milk as such is harmful (Elwood et al. 2004). Others have even shown positive metabolic effects associated with the intake of dairy products (Smedman et al. 1999; Mennen et al. 2000; Ness et al. 2001; Pereira et al. 2002). One reason for this discrepancy may be that the populations studied consume different types of dairy products. For instance, in France with a low CHD mortality, cheese consumption is high, while in the Scandinavian countries with high CHD mortality, milk consumption is high.

Certain varieties of cheese are rich sources of saturated fat, which may be positively associated with an increased risk of heart disease (Hu et al. 1999), but some are also rich sources of $\mathrm{Ca}$. $\mathrm{Ca}$ has been associated with a plasma lipid profile predictive of a lower risk of CHD (Jacqmain et al. 2003). Cheese is a fermented product, and it has been claimed that the consumption of fermented dairy products modulates cholesterol concentration (St Onge et al. 2000).

In addition, the bacteria involved in the ripening process may produce metabolites in the products, for instance folic acid (Forssen et al. 2000), that may affect serum homocysteine level (Appel et al. 2000). A high level of homocysteine in serum has been identified as a risk factor for CHD (Wald et al. 2002).

\footnotetext{
Abbreviations: BC, butter + calcium caseinate; BE, butter + egg-white protein; CH, cheese; FVII, factor VII coagulant activity; Lp (a), lipoprotein (a); PAI-1, plasminogen activator inhibitor type 1; TG, triacylglycerol; tPA, tissue plasminogen activator.

* Corresponding author: Professor Jan I. Pedersen, fax + 47228513 41, email j.i.pedersen@basalmed.uio.no
} 
Increased levels of markers of coagulation have been related to the development of CHD (Haverkate, 2002). Some studies have shown that haemostatic variables might be modified by diet (Marckmann, 2000), and it has been demonstrated in rats that butterfat in the diet may induce myocardial infarction from the thrombotic obstruction of coronary arteries (Thomas \& Hartroft, 1959; Hornstra, 1985). Impairment of fibrinolysis from the intake of butterfat has also been described in human plasma (Merigan et al. 1959). On the other hand, in one observational study it was found that the consumption of dairy products was beneficially associated with markers of fibrinolysis (Mennen et al. 1999).

Studies specifically examining the effects of cheese intake on the risk of CHD are scarce (Tavani et al. 2002). Some ecological studies have shown weak and non-significant negative correlations between cheese intake and heart disease rates (Artaud-Wild et al. 1993; Moss \& Freed, 2003). The potential relationship between cheese intake and traditional risk factors for CHD has, to our knowledge, been investigated only in one intervention study (Tholstrup et al. 2004) that indicated that cheese has a moderate cholesterol-lowering effect compared with butter. Thus, the present study was performed to further investigate the effect of cheese compared with butter on serum lipids, lipoproteins, homocysteine and haemostatic risk factors for CHD.

\section{Methods}

\section{Subjects and study design}

Thirty-three individuals, nine men and twenty-four women, were recruited among students at the University College of Akershus. Some of the subjects were also cohabitants of the students ( $n$ 3), and relatives or friends of members of the project group $(n 3)$. Criteria for inclusion were that the participants should be reliable, without serious illness that could influence the results, and have a regular meal pattern. There were no screening criteria with regard to sex, age, smoking habits, physical activity or body weight. Body weight and height were measured, and BMI was calculated as weight $(\mathrm{kg}) /$ height $(\mathrm{m})^{2}$. Body weight in the fasting state was measured at baseline, and after each intervention period, and also in the non-fasting state before dinner twice weekly. A food-frequency questionnaire was filled in by the subjects and showed that all subjects had ordinary dietary habits. A questionnaire about physical activity was filled in to calculate the subjects' energy level. Some participants used medications: drugs against asthma ( $n$ 2), allergy ( $n$ 3), menopausal problems $(n 1)$, depression ( $n 1)$ and epilepsy $(n 1)$. Two participants used oral contraceptives.

The study was a randomised three-period cross-over study which started in September 2001 and ended in December 2001. The participants were randomised into three groups and received three strictly controlled diets during periods of 3 weeks each. The diets contained three different test components: (A) cheese ( $\mathrm{CH}$ diet), (B) butter + casein (as calcium caseinate) (BC diet) and (C) butter + egg-white (BE diet), consumed in one of three sequences $(\mathrm{ABC}, \mathrm{BCA}, \mathrm{CAB})$. The intervention periods were separated by a 1-week period when subjects ate their habitual diet. The participants were requested to maintain their levels of physical activity and their smoking habits during the study, and were told to abstain from alcohol consumption. No payment was given, but the participants received free food. The study was performed in accordance with the Helsinki Declaration and the study protocol was approved by the Regional Committee for Ethics in Biomedical Research. All participants gave their written, informed consent.

\section{Experimental diets}

Three diets were designed by using a computer-based, nutrient-calculation program ('Mat på data' 3.0c; the National Association for Nutrition and Health, Oslo, Norway). The three test diets were isoenergetic, based on traditional Norwegian food, and consisted of a carefully planned, $7 \mathrm{~d}$ recycling menu of four main meals per $\mathrm{d}$. They were designed to have the same nutrient composition, and were calculated to contain $28 \%$ energy from fat, $26 \%$ energy from protein and $46 \%$ energy from carbohydrate. Of the fat, $20 \%$ energy came from the dairy product under study, and $8 \%$ energy from sources other than the test fat. Menus for the three experimental diets contained the same basic food items; meat, fish, bread, vegetables, fruit etc. They were all identical except for the different test component. The cheese was a Norwegian Swiss-type cheese ('Jarlsberg') which was taken from the production line. It was consumed 3-5 months after the production day. The bacteria strains used in the fermentation of Jarlsberg cheese are: Lactococcus lactis subsp. cremoris, L. lactis subsp. lactis, L. lactis subsp. lactis biovar diacetylactis, Leuconostoc mesenteorides subsp. cremoris and Propionibacterium freudenreichii. The casein used was in the form of calcium caseinate powder, and the egg-white was also in the form of powder. All were ordinary products produced for the market. The test components (cheese, butter, calcium caseinate and egg-white) were supplied to the menus as spreads, bread and sauce.

Dinner was for most of the participants eaten at the school kitchen during weekdays, whereas pre-packed breakfasts, lunches, snacks, and weekend meals were supplied to be eaten at home. No foods other than those provided were allowed during the controlled feeding periods. Tea and mineral water with artificial sweeteners were allowed. Coffee was allowed in restricted amounts (not more than two cups/d). The subjects were supplied with free food to meet $100 \%$ of their daily energy requirements. The diets were served according to five different energy levels; $7 \cdot 5,8,10,12.5$, and $15 \mathrm{MJ}$. The intake of cheese and butter on the $8 \mathrm{MJ}$ diets was 150 and $52 \mathrm{~g} / \mathrm{d}$, respectively, which corresponds to a fat intake from cheese or butter of $42 \mathrm{~g} / \mathrm{d}$.

Duplicate portions corresponding to an energy intake of $8 \mathrm{MJ}$ were collected of all three diets for $7 \mathrm{~d}$ and kept at $-20^{\circ} \mathrm{C}$ until they were homogenised and freeze-dried. The seven homogenates from each diet were pooled and samples of the three diets were analysed for their content of fat, protein, cholesterol, $\mathrm{Ca}$ and fatty acid composition. 


\section{Chemical analysis}

The content of total fat in the duplicate portions was determined by chloroform-methanol extraction (Folch et al. 1957). The N content was determined by the Kjeldahl technique. The factor used for the conversion of $\mathrm{N}$ content to protein was $6 \cdot 30$. The extracted fatty acids from the duplicate portions were methylated with benzene and methanolic $\mathrm{HCl}$ (3 M) using the method of Hoshi et al. (1973) and analysed by GC.

\section{Blood sampling and analysis}

Blood samples were drawn after an overnight fast immediately before breakfast at baseline and twice (on two following days) at the end of each diet period. The mean of the two values from the end of each period was used. Baseline blood samples were not drawn for the analysis of lipoprotein (a) (Lp (a)) and haemostatic variables. Blood samples were drawn with minimal stasis using the Vacutainer system and analysed for lipids, haemostatic variables and homocysteine. All samples from a given individual were analysed in the same batch.

Serum for lipid analyses was obtained by centrifugation at $2500 \mathrm{~g}$ for $15 \mathrm{~min}$ at $4^{\circ} \mathrm{C}$ within $1 \mathrm{~h}$ of venepuncture and stored at $-70^{\circ} \mathrm{C}$ until analysed. Total cholesterol and triacylglycerols (TG) was measured by enzymic methods using commercial kits (Technicon reagent T01-1684-02 and Technicon reagent T01-1868-02; Bayer, Tarrytown, NY, USA). Serum HDL-cholesterol was measured directly by a detergent-containing method. This detergent solublises only HDL while non-HDL lipoproteins are inhibited from reacting with the enzymes (Liquid N-geneous HDL-c reagent; Genzyme Diagnostics, West Malling, Kent, UK). All the lipid analyses were spectrophotometric, using automated analyser equipment (Technicon RA 1000; Tarrytown, NY, USA). The interassay CV were as follows $(\%)$ : total cholesterol, 0.9; HDL, 2.4; TG, 1.5. Serum LDL-cholesterol was calculated using the Friedewald equation (Friedewald et al. 1972). Serum apo A-I and apo B were both quantified by an immunochemical method and measured by nephelometry ( $\mathrm{N}$ antisera to human apo A-I and apo B; Dade Behring Marburg $\mathrm{GmbH}$, Marburg, Germany) with CV of 4.5 and $4.6 \%$ respectively. Lp (a) was quantified by a commercial kit (TintElize Lp (a); Biopool AB, Umeå, Sweden) according to the manufacturer's instructions. The interassay $\mathrm{CV}$ was $2.7 \%$.

Citrated plasma for analyses of the fibrinolytic factors plasminogen activator inhibitor type 1 (PAI-1) activity, PAI-1 antigen and tissue plasminogen activator (tPA) antigen, and the coagulation factors fibrinogen, factor VII coagulant activity (FVII) and prothrombin fragment $1+2$ was obtained by Vacutainer tubes containing $0.129 \mathrm{mmol}$ trisodium citrate/l in dilution 1:10. Plasma for analyses of tPA activity was obtained by using Stabilyte tubes as described by Ranby et al. (1989b). All samples except those for FVII analysis were kept on ice and separated by centrifugation at $2500 \mathrm{~g}$ for $15 \mathrm{~min}$ at $4^{\circ} \mathrm{C}$. Citrated plasma for the determination of FVII was handled at room temperature to avoid cold activation. All samples were stored at $-70^{\circ} \mathrm{C}$ until analysed.
PAI-1 activity, PAI-1 antigen, t-PA activity and t-PA antigen were measured using commercially available kits (Spectrolyse/pL, TintElize PAI-1, Chromolize tPA and TintElize tPA, respectively; Biopool AB, Umeå, Sweden). FVII was measured using a commercially available chromogenic assay (COASET FVII; Chromogenix, Chromogenix-Instrumentation Laboratory SpA, Milan, Italy). Fibrinogen was measured according to Clauss (1957) using an ACL-3000 Coagulation system Analyser (Instrumentation Laborator, Milan, Italy). Prothrombin fragment $1+2$ was measured by an enzyme immunoassay (Enzygnost F1 + 2 micro; Behringwerke AG, 35001 Marburg, Germany). Interassay CV were as follows (\%): tPA antigen, 3.5; tPA activity, 8.0; PAI-1 antigen, 9.8; PAI-1 activity, 4.8; fibrinogen, 3.6; FVII, $3 \cdot 1$; prothrombin fragment $1+2,8 \cdot 2$.

Plasma for homocysteine analyses was obtained by centrifugation at $1800 \mathrm{~g}$ for $10 \mathrm{~min}$ at $4^{\circ} \mathrm{C}$ directly after venepuncture and stored at $-70^{\circ} \mathrm{C}$ until analysed. Heparin was used as an anticoagulant. Total homocysteine (free and protein-bound) was determined by HPLC using a commercial kit from Bio-Rad (Bio-Rad Laboratories $\mathrm{GmbH}$, Munich, Germany). The interassay CV was $5 \%$.

\section{Statistical methods}

The results are presented as mean values and standard deviations. To compare the effects of the three diets, repeated measures ANOVA was applied (general linear model univariate procedure in SPSS). In addition to diet, period was included in the models to test for systematic differences between the three intervention periods. No period effects were found, thus this was removed from the models. When a statistically significant effect of diet was found, pair-wise comparisons between the three diets were performed with the Bonferroni correction. Plasma Lp (a) and tPA antigen were $\log _{\mathrm{e}}$-transformed. All $P$ values are two-sided, and a $5 \%$ level of significance was used. All data analyses were performed with SPSS version 11.0 (SPSS Inc., Chicago, IL, USA).

\section{Results}

\section{Subjects}

Of the thirty-three individuals recruited, six dropped out at the start of the study either because they disliked the diet or because of personal practical problems. Three more withdrew during the first period because of family illness and compliance problems. The remaining twenty-four individuals, nine men and fifteen women, mean age 31.5 (range 21-54) years, participated in the study. The mean BMI was 27 (range 19-37) $\mathrm{kg} / \mathrm{m}^{2}$ and their mean waist:hip ratio was 0.8 (range $0.7-1 \cdot 0$ ). The results from two individuals had to be excluded because of unacceptable weight loss. The final analyses are thus based on the results from twenty-two individuals. Compliance with the diets was judged by direct observation of the consumption of weekday dinners, and by the evaluation of food diaries. The mean fasting body weights after each of the three dietary periods did not differ notably (CH diet 78.1 (SD 17.2) $\mathrm{kg}, \mathrm{BC}$ diet $78 \cdot 1$ (SD 17.0) $\mathrm{kg}$, BE diet $77 \cdot 8$ (SD 17.1) $\mathrm{kg}$ ). 


\section{Test diets}

The results of duplicate portions of the three diets are given in Table 1. The energy content was somewhat higher than the calculated $8 \mathrm{MJ}$. The proportions of fat in the diets were slightly lower than originally calculated in the $\mathrm{CH}$ and $\mathrm{BC}$ diets, and the proportion of protein was slightly higher than calculated in the $\mathrm{CH}$ diet. The content of $\mathrm{Ca}$ was not calculated when the diets were planned, and differed in the three diets with the highest intake from the $\mathrm{CH}$ diet $(2108 \mathrm{mg} / \mathrm{d})$ and the lowest intake from the BE diet $(830 \mathrm{mg} / \mathrm{d})$.

The fatty acid compositions of the test diets are shown in Table 2. The three diets contained similar amounts of the different fatty acids. Of all fatty acids, $60.5 \%$ were saturated, $29 \%$ monounsaturated and $10.5 \%$ polyunsaturated.

Table 1. Content of energy and nutrients of duplicate portions of the test diets

\begin{tabular}{lrrr}
\hline & CH diet & BC diet & BE diet \\
\hline Energy (MJ) & 8.5 & 8.5 & 8.7 \\
Protein (\% energy) & 25.3 & 21.5 & 21.6 \\
Fat (\% energy) & 26.2 & 26.2 & 27.7 \\
Cholesterol (mg/d) & 225 & 215 & 226 \\
Ca (mg/d) & 2108 & 1143 & 830 \\
\hline
\end{tabular}

$\mathrm{CH}$, cheese; $\mathrm{BC}$, butter + casein; $\mathrm{BE}$, butter + egg-white.

Table 2. Fatty acid composition ( $\mathrm{g} / 100 \mathrm{~g}$ fatty acids) of the test diets

\begin{tabular}{|c|c|c|c|}
\hline Fatty acid & $\mathrm{CH}$ diet & BC diet & BE diet \\
\hline $4: 0$ & $2 \cdot 8$ & $2 \cdot 9$ & $3 \cdot 1$ \\
\hline $6: 0$ & 1.9 & 1.9 & 1.9 \\
\hline $8: 0$ & $1 \cdot 1$ & $1 \cdot 1$ & 1.0 \\
\hline $10: 0$ & $2 \cdot 3$ & $2 \cdot 2$ & $2 \cdot 0$ \\
\hline $12: 0$ & $2 \cdot 7$ & 2.5 & $2 \cdot 4$ \\
\hline $14: 0$ & 9.3 & $9 \cdot 3$ & $8 \cdot 8$ \\
\hline $14: 1 n-5$ & 0.7 & 0.8 & 0.7 \\
\hline $15: 0$ & 0.8 & 0.8 & 0.8 \\
\hline $16: 0$ & $26 \cdot 6$ & $26 \cdot 4$ & $25 \cdot 8$ \\
\hline $16: 1 n-7$ & 1.4 & 1.4 & $1 \cdot 3$ \\
\hline $16: 1$ trans & 0.1 & 0.1 & 0.1 \\
\hline $17: 0$ & 0.5 & 0.5 & 0.5 \\
\hline $17: 1$ & 0.3 & 0.3 & 0.3 \\
\hline $18: 0$ & $11 \cdot 7$ & $12 \cdot 3$ & 12.5 \\
\hline $18: 1 n-9$ & $23 \cdot 9$ & 24.5 & 24.5 \\
\hline $18: 1 n-7$ & $2 \cdot 6$ & $2 \cdot 8$ & 3.4 \\
\hline $18: 1$ trans & $2 \cdot 7$ & $3 \cdot 0$ & $2 \cdot 9$ \\
\hline $18: 2 n-6$ & 8.0 & $6 \cdot 6$ & $7 \cdot 4$ \\
\hline $18: 2$ trans & 0.1 & 0.1 & 0.1 \\
\hline $18: 2$ conjugated & 0.4 & 0.4 & 0.4 \\
\hline $19: 1$ & 0.1 & 0.1 & 0.1 \\
\hline $18: 3 n-3$ & 1.3 & $1 \cdot 2$ & $1 \cdot 1$ \\
\hline $18: 4$ & 0.7 & 0.9 & 0.9 \\
\hline $20: 0$ & 0.2 & 0.2 & 0.2 \\
\hline $20: 1 n-9$ & 0.2 & 0.3 & 0.2 \\
\hline $20: 3 n-6$ & 0.1 & 0.1 & 0.1 \\
\hline $20: 4 n-6$ & 0.1 & 0.1 & 0.1 \\
\hline $20: 5 n-3$ & 0.1 & 0.1 & 0.1 \\
\hline $22: 0$ & 0.1 & 0.1 & 0.1 \\
\hline $22: 1 n-9$ & 0.1 & 0 & 0.1 \\
\hline $22: 5 n-3$ & 0.1 & 0.1 & 0.1 \\
\hline $24: 0$ & 0.1 & 0.1 & 0.1 \\
\hline $22: 6 n-3$ & 0.1 & 0.1 & 0.1 \\
\hline
\end{tabular}

$\mathrm{CH}$, cheese; $\mathrm{BC}$, butter + casein; $\mathrm{BE}$, butter + egg-white.

\section{Serum lipids and lipoproteins}

The concentrations of total, LDL- and HDL-cholesterol, the total cholesterol:HDL-cholesterol ratio, TG, apo A-I, apo B and Lp (a) at baseline and after the three test diets are shown in Table 3. Lp (a) was not analysed at baseline. Only total cholesterol concentration was significantly different between the diets $(P=0 \cdot 04)$. We found a significantly lower level after the $\mathrm{CH}$ period than after the $\mathrm{BC}$ period (difference between means -0.27 (95\% CI $-0.52, \quad-0.015) \mathrm{mmol} / \mathrm{l} ; \quad P=0.03)$. The results also showed a reduction in LDL-cholesterol after the $\mathrm{CH}$ diet compared with the BC diet, but this result was not significant (difference between means $-0.22(95 \% \mathrm{CI}-0.44$, $0 \cdot 00) \mathrm{mmol} / \mathrm{l} ; P=0 \cdot 06)$.

\section{Haemostatic variables and homocysteine}

The concentrations of haemostatic variables and homocysteine at baseline and after the three test diets are shown in Table 4. Baseline values for tPA activity, tPA antigen, PAI-1 activity, PAI-1 antigen, FVII, fibrinogen and prothrombin fragment $1+2$ were not analysed. The only haemostatic variable showing a significant difference between the diets was fibrinogen $(P=0 \cdot 04)$. However, one subject had an extremely high fibrinogen level on the $\mathrm{CH}$ diet compared with the $\mathrm{BC}$ and $\mathrm{BE}$ diets, and when the results from this subject were excluded from the dataset, no significant difference was found between the diets $(P=0 \cdot 12)$. There was no significant difference in homocysteine levels between the diets $(P=0 \cdot 14$; Table 4$)$.

\section{Discussion}

The results from the present strictly controlled dietary study indicate that, at equal fat content, cheese may be less cholesterol increasing than butter. The LDL:HDL ratio, however, showed no difference between the diets. When haemostatic variables and homocysteine are considered, the results from the present study do not show any beneficial effect from cheese compared with butter.

As far as we know, only one similar intervention study comparing the effects of cheese and butter on CHD risk factors has been published previously (Tholstrup et al. 2004). Also in that study, on fourteen healthy young men, the intake of a cheese diet resulted in $0.21 \mathrm{mmol} / \mathrm{l}$ lower LDL-cholesterol than the intake of a butter diet $(P=0.037)$, with a borderline significant difference in total cholesterol $(0.20 \mathrm{mmol} / \mathrm{l} ; P=0.054)$.

Only a few ecological and observational studies have investigated the association between the intake of cheese and the risk of $\mathrm{CHD}$, and the results from these studies are contradictory. The Oxford Vegetarian Study, a prospective cohort study, showed a positive association between the intake of cheese and total cholesterol in both men and women, and also a positive association between the intake of cheese and IHD mortality in vegetarians (Appleby et al. 1999). Moss \& Freed (2003) reported in their ecological study a strong positive correlation between milk-consumption figures for 1989 and heart disease death rates in 1993 in some Organisation for Economic Co-operation and Development countries, while cheese intake was 
Table 3. Serum lipoprotein levels at baseline and at the end of the dietary test periods for twenty-two participants (Mean values and standard deviations)

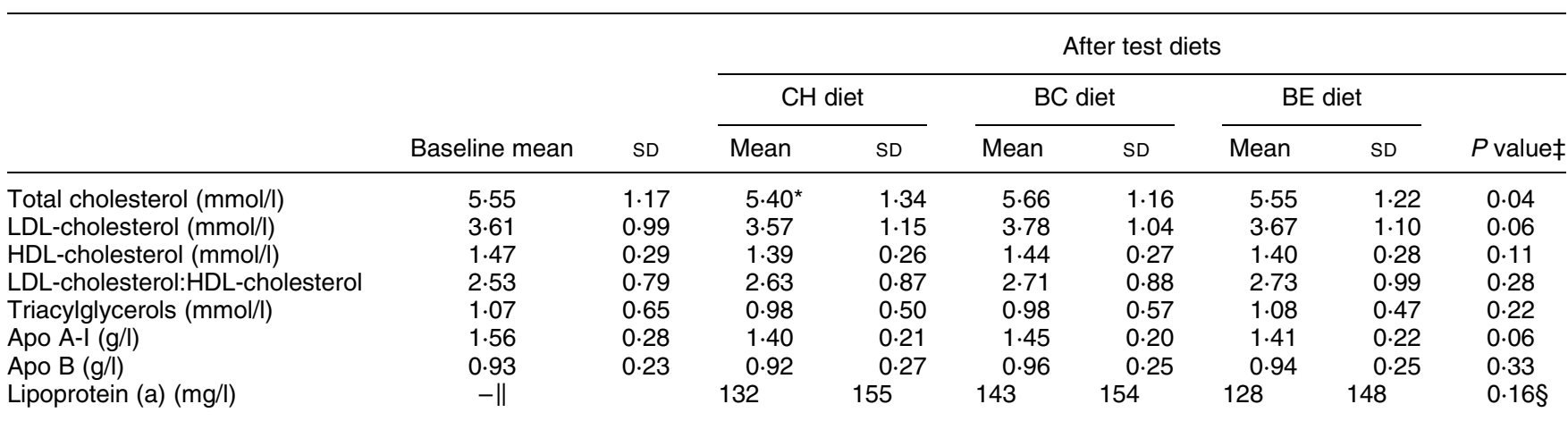

$\mathrm{CH}$, cheese; $\mathrm{BC}$, butter + casein; $\mathrm{BE}$, butter + egg-white

* Mean value was significantly different from that after the BC diet $(P=0.03)$.

†For details of diets and procedures, see Tables 1 and 2 and p. 793.

$\ddagger$ Effect of diet (repeated measures ANOVA).

$\S$ The analysis was performed on $\log _{e}$-transformed data.

I| Baseline value for lipoprotein (a) was not analysed.

non-significantly negatively correlated. Furthermore, a case-control study conducted in Italy reported that men and women in the highest tertile for cheese intake were no more likely to have had a myocardial infarction than individuals in the lowest tertile (Tavani et al. 2002). In an observational study from Sweden, a significant negative association was found between the intake of cheese and serum cholesterol levels among adolescent boys (Samuelson et al. 2001).

In the present study the three diets differed in $\mathrm{Ca}$ with the highest intake from the $\mathrm{CH}$ diet $(2108 \mathrm{mg} / \mathrm{d})$, the lowest from the $\mathrm{BE}$ diet $(830 \mathrm{mg} / \mathrm{d})$ and the $\mathrm{BC}$ diet in between $(1143 \mathrm{mg} / \mathrm{d})$ (Table 1$)$. One possible mechanism behind the present findings could be that dietary Ca promotes the excretion of fat as Ca soaps in faeces (Renaud \& Lanzmann-Petithory, 2001; Lorenzen et al. 2004). Our diets were not balanced in $\mathrm{Ca}$ content for the reason that we were interested in investigating the effect of cheese and butter as food products, and not single nutrients, on risk factors for CHD. Yacowitz et al. (1965) showed a significant decrease in both serum cholesterol and TG levels in subjects with an increased ingestion of $\mathrm{Ca}$, and could furthermore demonstrate an increase in total faecal lipids. Also Bhattacharyya et al. (1969) found a significant decrease in serum cholesterol after the intake of a high$\mathrm{Ca}$ high-saturated-fat diet compared with a low-Ca highsaturated-fat diet.

St Onge et al. (2000) examined the available literature supporting the claim that the consumption of fermented dairy products modulates cholesterol concentrations and found a moderate cholesterol-lowering action of such products. In that review some possible mechanisms behind the findings are pointed out. One necessary condition is that the bacteria are able to survive the gut and colonise the intestine (i.e. be probiotic). Once in the large intestine, bacteria ferment indigestible carbohydrates and produce SCFA

Table 4. Haemostatic variables and homocysteine levels at baseline and at the end of the dietary test periods for twenty-two participants (Mean values and standard deviations)

\begin{tabular}{|c|c|c|c|c|c|c|c|c|c|}
\hline & \multirow[b]{3}{*}{ Baseline mean† } & \multirow[b]{3}{*}{ SD } & \multicolumn{7}{|c|}{ After test diets } \\
\hline & & & \multicolumn{2}{|c|}{$\mathrm{CH}$ diet } & \multicolumn{2}{|c|}{ BC diet } & \multicolumn{2}{|c|}{ BE diet } & \multirow[b]{2}{*}{$P$ value $\neq$} \\
\hline & & & Mean & SD & Mean & SD & Mean & SD & \\
\hline tPA activity (IU/ml) & & & 0.92 & 0.53 & 0.78 & 0.58 & 0.96 & 0.46 & 0.63 \\
\hline tPA antigen (ng/ml) & & & $6 \cdot 0$ & $3 \cdot 8$ & $6 \cdot 2$ & 3.6 & $6 \cdot 1$ & $3 \cdot 2$ & $0.23 \S$ \\
\hline PAl-1 activity (U/ml) & & & $10 \cdot 6$ & $12 \cdot 2$ & $13 \cdot 0$ & $10 \cdot 7$ & $10 \cdot 2$ & $7 \cdot 0$ & 0.21 \\
\hline $\mathrm{PAl}-1$ antigen $(\mathrm{ng} / \mathrm{ml})$ & & & $13 \cdot 6$ & $12 \cdot 3$ & $14 \cdot 8$ & $11 \cdot 6$ & $12 \cdot 8$ & $10 \cdot 0$ & 0.57 \\
\hline Factor VIIC (\%) & & & 100 & 30 & 101 & 29 & 104 & 30 & 0.69 \\
\hline Fibrinogen $(g / l)$ & & & 2.67 & 0.51 & 2.55 & 0.45 & 2.50 & 0.43 & $0.04 \|$ \\
\hline Prothrombin fragment $1+2(\mathrm{nmol} / \mathrm{l})$ & & & 0.78 & 0.58 & 0.65 & 0.20 & 0.80 & 0.41 & 0.22 \\
\hline Homocysteine $(\mu \mathrm{mol} / \mathrm{l})$ & $9 \cdot 34$ & 2.54 & $9 \cdot 04$ & 2.58 & 8.82 & $2 \cdot 15$ & $8 \cdot 41$ & 1.83 & 0.14 \\
\hline
\end{tabular}

$\mathrm{CH}$, cheese; $\mathrm{BC}$, butter + casein; BE, butter + egg-white; tPA, tissue plasminogen activator; PAI, plasminogen activator inhibitor.

${ }^{*}$ For details of diets and procedures, see Tables 1 and 2 and p. 793.

† Baseline values for tPA activity, tPA antigen, PAl-1 activity, PAl-1 antigen, factor VIlc, fibrinogen and prothrombin fragment $1+2$ were not analysed.

$\ddagger$ Effect of diet (repeated measures ANOVA).

$\S$ The analysis was performed on $\log _{\mathrm{e}}$-transformed data.

$\| P=0.12$ after exclusion of one subject with an extremely high level of fibrinogen after the $\mathrm{CH}$ diet (see p. 794). 
which are absorbed and influence cholesterol metabolism in the liver (Wolever et al. 1996). Also, the intestinal bacteria can bind bile acids to cholesterol, resulting in the excretion of bile acid-cholesterol complexes in the faeces (St Onge et al. 2000).

Many probiotic bacterial strains have been investigated for their cholesterol-lowering potential, but the results are inconclusive (de Roos \& Katan, 2000). One of the bacterial strains used in the fermentation of Jarlsberg cheese, $L$. lactis subsp. cremoris, was found to have a hypocholesterolaemic effect in rats when skimmed milk fermented with this bacterial stain was compared with chemically acidified skimmed milk (Nakajima et al. 1992). Whether this strain can survive the gut and colonise the intestine in man is not known. The propionic acid bacteria are shown to adhere to the intestinal epithelial tissue (Zarate et al. 2002), and $P$. freudenreichii, the propionic acid bacterial strain used in Swiss-type cheeses has also been shown to stay alive through the gut (Ouwehand et al. 2001) and may exert an effect in the intestine. The propionic acid bacteria $(P$. shermanii subsp. freudenreichii INF- $\alpha$ ) used in Jarlsberg cheese has never been tested for probiotic properties or cholesterol-lowering potential.

Casein, the main protein in milk and dairy foods, is reported to be hypercholesterolaemic when substituted for soya protein, although the effect of casein on blood cholesterol levels varies widely in different studies and appears to depend on experimental conditions (Forsythe et al. 1986). In the present study, the content of protein, and thereby casein, was higher in the $\mathrm{CH}$ diet than in the $\mathrm{BC}$ diet, so the cholesterol-increasing effect of the $\mathrm{BC}$ diet can not be explained by the content of casein.

As far as we know, only one study has investigated the association between haemostatic variables and the intake of cheese. Mennen et al. (1999) reported from a prospective cohort study an inverse association between cheese consumption and tPA antigen in both men and women. PAI1 and tPA are factors involved in the fibrinolytic system, tPA enhancing the fibrinolysis, and PAI-1 inhibiting it by binding to tPA. A high level of tPA activity is beneficial with respect to CVD because tPA activates plasminogen and thereby leads to the degradation of fibrin and thrombi. However, when IPA is measured as tPA antigen it reflects mainly the complex of tPA and PAI-1 which indicates the inhibition of fibrinolysis (Ranby et al. 1989a). The present results do not support the findings of Mennen et al. (1999) of an association between the intake of cheese and the inhibition of fibrinolysis.

Serum homocysteine levels are influenced by the intake of folic acid, vitamin $\mathrm{B}_{6}$ and vitamin $\mathrm{B}_{12}$ (Appel et al. 2000), and raised homocysteine concentrations have been proposed as a risk factor for CVD (O'Grady et al. 2002). Results from the Dietary Approaches to Stop Hypertension trial showed that a diet high in fruit, vegetables and low-fat dairy products could lower fasting levels of serum homocysteine (Appel et al. 2000). The present results did not show any differences in serum homocysteine between the three diets.

To conclude, we have shown that cheese may be less cholesterol increasing than butter with identical fat content. No differences were found in haemostatic risk factors.
Further studies are needed to verify the present results and to elucidate the possible mechanisms behind the present findings of the differential effects on serum cholesterol of cheese and butter.

\section{Acknowledgements}

We gratefully acknowledge the cooperation of the participants in the study. We thank Annbjørg Lindbäck, Anja Schou Lindman, and the kitchen staff for their assistance, Bente Braathen and Turid Veggan for drawing and handling the blood samples, and Anne Randi Alvestad for drawing and handling the blood samples and for help with the lipid analyses. The study was supported financially by the Research Council of Norway, the dairy company TINE BA, that also provided milk, yoghurt, butter and cheese, and the Norwegian Meat Marketing Board and Fellesjuice AS that provided juice products.

\section{References}

Appel LJ, Miller ER III, Jee SH, Stolzenberg-Solomon R, Lin PH, Erlinger T, Nadeau MR \& Selhub J (2000) Effect of dietary patterns on serum homocysteine: results of a randomized, controlled feeding study. Circulation 102, 852-857.

Appleby PN, Thorogood M, Mann JI \& Key TJ (1999) The Oxford Vegetarian Study: an overview. Am J Clin Nutr 70, 525S-531S.

Artaud-Wild SM, Connor SL, Sexton G \& Connor WE (1993) Differences in coronary mortality can be explained by differences in cholesterol and saturated fat intakes in 40 countries but not in France and Finland. A paradox. Circulation 88, $2771-2779$.

Bhattacharyya AK, Thera C, Anderson JT, Grande F \& Keys A (1969) Dietary calcium and fat. Effect on serum lipids and fecal excretion of cholesterol and its degradation products in man. Am J Clin Nutr 22, 1161-1174.

Clauss A (1957) Gerinnungsphysiologische schnellmetode zur bestimmung des fibrinogens (Rapid physiological coagulation method in determination of fibrinogen). Acta Haematol 17, 237-246.

de Roos NM \& Katan MB (2000) Effects of probiotic bacteria on diarrhea, lipid metabolism, and carcinogenesis: a review of papers published between 1988 and 1998. Am J Clin Nutr 71, 405-411.

Elwood PC, Pickering JE, Hughes J, Fehily AM \& Ness AR (2004) Milk drinking, ischaemic heart disease and ischaemic stroke II. Evidence from cohort studies. Eur J Clin Nutr 58, $718-724$.

Folch J, Lees M \& Sloane-Stanley GH (1957) A simple method for the isolation and purification of total lipides from animal tissues. J Biol Chem 226, 497-509.

Forssen KM, Jagerstad MI, Wigertz K \& Witthoft CM (2000) Folates and dairy products: a critical update. $J$ Am Coll Nutr 19, 100S-110S.

Forsythe WA, Green MS \& Anderson JJ (1986) Dietary protein effects on cholesterol and lipoprotein concentrations: a review. J Am Coll Nutr 5, 533-549.

Friedewald WT, Levy RI \& Fredrickson DS (1972) Estimation of the concentration of low-density lipoprotein cholesterol in plasma, without use of the preparative ultracentrifuge. Clin Chem 18, 499-502.

Haverkate F (2002) Levels of haemostatic factors, arteriosclerosis and cardiovascular disease. Vascul Pharmacol 39, 109-112.

Hegsted DM, Ausman LM, Johnson JA \& Dallal GE (1993) 
Dietary fat and serum lipids: an evaluation of the experimental data. Am J Clin Nutr 57, 875-883.

Hornstra G (1985) Dietary lipids, platelet function and arterial thrombosis in animals and man. Proc Nutr Soc 44, 371-378.

Hoshi M, Williams M \& Kishimoto Y (1973) Esterification of fatty acids at room temperature by chloroform-methanolic HCl-cupric acetate. J Lipid Res 14, 599-601.

Hu FB, Stampfer MJ, Manson JE, Ascherio A, Colditz GA, Speizer FE, Hennekens CH \& Willett WC (1999) Dietary saturated fats and their food sources in relation to the risk of coronary heart disease in women. Am J Clin Nutr 70, 1001-1008.

Jacqmain M, Doucet E, Despres JP, Bouchard C \& Tremblay A (2003) Calcium intake, body composition, and lipoproteinlipid concentrations in adults. Am J Clin Nutr 77, 1448-1452.

Katan MB, Zock PL \& Mensink RP (1995) Dietary oils, serum lipoproteins, and coronary heart disease. Am J Clin Nutr 61, 1368S-1373S.

Kris-Etherton PM \& Yu S (1997) Individual fatty acid effects on plasma lipids and lipoproteins: human studies. Am J Clin Nutr 65, 1628S-1644S.

Kushi LH, Lenart EB \& Willett WC (1995) Health implications of Mediterranean diets in light of contemporary knowledge. 1. Plant foods and dairy products. Am J Clin Nutr 61, 1407S-1415S.

Lorenzen JK, Jacobsen R \& Astrup A (2004) Effect of short-term high dietary calcium intake on 24-h energy expenditure, fat oxidation, and fecal fat excretion. Int J Obes 28, Suppl. 1, S34.

Marckmann P (2000) Dietary treatment of thrombogenic disorders related to the metabolic syndrome. $\mathrm{Br} J \mathrm{Nutr} \mathbf{8 3}$, Suppl. 1, S121-S126.

Mennen LI, Balkau B \& Vol S (1999) Tissue-type plasminogen activator antigen and consumption of dairy products. The DESIR study. Thromb Res 94, 381-388.

Mennen LI, Lafay L, Feskens EJM, Novak M, Lépinay P \& Balkau B (2000) Possible protective effect of bread and dairy products on the risk of the metabolic syndrome. Nutr Res $\mathbf{2 0}$, $335-347$.

Merigan TC, Farquhar JW, Williams JH \& Sokolow M (1959) Effect of chylomicrons on the fibrinolytic activity of normal human plasma in vitro. Circ Res 7, 205-209.

Moss M (2002) Does milk cause coronary heart disease? J Nutr Environ Med 12, 207-216.

Moss M \& Freed D (2003) The cow and the coronary: epidemiology, biochemistry and immunology. Int $J$ Cardiol 87, 203-216.

Nakajima H, Suzuki Y \& Hirota T (1992) Cholesterol-lowering activity of ropy fermented milk. J Food Sci 57, 1327-1329.

Ness AR, Smith GD \& Hart C (2001) Milk, coronary heart disease and mortality. J Epidemiol Community Health 55, $379-382$.

O'Grady H, Kelly C, Bouchier-Hayes D \& Leahy A (2002) Homocysteine and occlusive arterial disease. Br J Surg 89, 838-844.
Ouwehand AC, Soumalainen T, Tøllkø S \& Salminen S (2001) In vitro adhesion of propionic acid bacteria to human intestinal mucus. Le Lait 82, 123-130.

Pereira MA, Jacobs DR Jr, van Horn L, Slattery ML, Kartashov AI \& Ludwig DS (2002) Dairy consumption, obesity, and the insulin resistance syndrome in young adults: the CARDIA study. JAMA 287, 2081-2089.

Pietinen P, Vartiainen E, Seppanen R, Aro A \& Puska P (1996) Changes in diet in Finland from 1972 to 1992: impact on coronary heart disease risk. Prev Med 25, 243-250.

Ranby M, Nguyen G, Scarabin PY \& Samama M (1989a) Immunoreactivity of tissue plasminogen activator and of its inhibitor complexes. Biochemical and multicenter validation of a two site immunosorbent assay. Thromb Haemost 61, 409-414.

Ranby M, Sundell IB \& Nilsson TK (1989b) Blood collection in strong acidic citrate anticoagulant used in a study of dietary influence on basal tPA activity. Thromb Haemost 62, 917-922.

Renaud S \& Lanzmann-Petithory D (2001) Coronary heart disease: dietary links and pathogenesis. Public Health Nutr 4, 459-474.

Samuelson G, Bratteby LE, Mohsen R \& Vessby B (2001) Dietary fat intake in healthy adolescents: inverse relationships between the estimated intake of saturated fatty acids and serum cholesterol. Br J Nutr 85, 333-341.

Smedman AEM, Gustafsson IB, Berglund LGT \& Vessby BOH (1999) Pentadecanoic acid in serum as a marker for intake of milk fat: relations between intake of milk fat and metabolic risk factors. Am J Clin Nutr 69, 22-29.

St Onge MP, Farnworth ER \& Jones PJ (2000) Consumption of fermented and nonfermented dairy products: effects on cholesterol concentrations and metabolism. Am J Clin Nutr 71, 674-681.

Tavani A, Gallus S, Negri E \& La Vecchia C (2002) Milk, dairy products, and coronary heart disease. $J$ Epidemiol Community Health 56, 471-472.

Tholstrup T, Hoy CE, Andersen LN, Christensen RD \& Sandstrom B (2004) Does fat in milk, butter and cheese affect blood lipids and cholesterol differently? J Am Coll Nutr 23, 169-176.

Thomas WA \& Hartroft WS (1959) Myocardial infarction in rats fed diets containing high fat, cholesterol, thiouracil, and sodium cholate. Circulation 19, 65-72.

Wald DS, Law M \& Morris JK (2002) Homocysteine and cardiovascular disease: evidence on causality from a meta-analysis. BMJ 325, 1202.

Wolever TM, Fernandes J \& Rao AV (1996) Serum acetate:propionate ratio is related to serum cholesterol in men but not women. J Nutr 126, 2790-2797.

Yacowitz H, Fleischman AI \& Bierenbaum ML (1965) Effect of oral calcium upon serum lipids in man. Br Med $\mathrm{J} \mathbf{i}, 1352-1354$.

Zarate G, Morata D, Chaia AP \& Gonzalez SN (2002) Adhesion of dairy propionibacteria to intestinal epithelial tissue in vitro and in vivo. J Food Prot 65, 534-539. 